\title{
NOVA ESPÉCIE DO GÊNERO TREMBLEYA DC. (MICROLICIEAE - MELASTOMATACEAE).'
}

\author{
ENEIDA MARTINS
}

Instituto de Biologia, Universidade Estadual de Campinas, C. Postal 6109, 13081970 - Campinas, SP, Brasil.

\begin{abstract}
A new species of the genus Trembleya DC. (Microlicieae-Melastomataceae)). A new species of Melastomataceae, Trembleya hatschbachii Wurdack et E. Martins is described and illustrated. Distribution is restricted to the region of Grão-Mogol, state of Minas Gerais, Brazil. This species may be distinguished from all others described for the genus by the yellow petals and by the elliptical leaf blades loosely distributed along the branch.

RESUMO - (Nova espécie do gênero Tremblẹ̣ DC. (Microlicieae-Melastomataceae)). São apresentadas a descrição e a ilustração de uma nova espécie de Melastomataceae, Trembleya hatschbachii Wurdack et E. Martins, cuja distribuição é restrita à região de Grão-Mogol, Minas Gerais, Brasil. A espécie pode ser reconhecida pelas pétalas amareladas e lâminas foliares elípticas laxamente distribuídas ao longo dos ramos.
\end{abstract}

Key words: Melastomataceae, Trembley, campo rupestre.

\section{INTRODUÇÃO}

O gênero Trembleya, com distribuição exclusiva no território brasileiro, compreende espécies subarbustivas e arbustivas, em sua maioria restritas aos campos rupestres da Cadeia do Espinhaço, em Minas Gerais, e da Serra dos Pirineus, em Goiás. Segundo Cogniaux (1883), apresenta 14 espécies. Entretanto, estudos preliminares de revisão taxonômica deste gênero (Martins, em prep.) revelam 19 espécies descritas até agora. O reconhecimento de uma nova espécie, referida até o momento para Grão-Mogol, já havia sido feito por Wurdack (com.pes.). Após o exame de materiais provenientes de 23 herbários nacionais e estrangeiros, foi possível confirmar a existência desta espécie como distinta das demais já descritas, pela coloração amarela das pétalas associada à presença de folhas elípticas e não imbricadas.

\footnotetext{
' Parte da tese de doutorado, em desenvolvimento no Departamento de Botânica do Instituto de Biologia da UNICAMP, sob orientação da Dra. Angela Borges Martins, com bolsa da CAPES.
} 


\section{DESCRIÇÃO DA ESPÉCIE}

Trembleya hatschbachii Wurdack et E. Martins, sp. nov.

Figs. 1-6

Frutex erectus, glabrus, dense glutinosus. Foliorum petioli $0,8-1,3 \mathrm{~cm}$ longi, graciles; laminae plerumque 5,0-7,5cm longae, 2,0-3,5cm latae, ellipticae, apice hebeti-acuto, basi late acuta, firme chartaceae, ad marginem integrae, glabratae, 5nervatae (pare exteriori inframarginali incluso). Paniculae in foliorum axillis, 5,09,0cm longae, diffusae, bracteatae, floribus 6-10; pedicelli (supra bracteolarum) ca. 2,0-3,0mm longi. Petala flava, 7,8-7.9mm longa, 6,8-7,0mm lata. Ovarium 5-loculare.

Arbustos 1,5-2,0m alt., eretos, glabros e densamente glutinosos. Ramos tetragonos e canaliculados. Folhas pecioladas; pecíolos 7,0-16,0 mm compr., delicados; lâmina 5,0-7,5cm compr., 2,0-3,5cm larg., cartácea, elíptica, base atenuada, ápice agudo, margem íntegra, 5-nérvea (incluindo o par externo inframarginal). Panículas dicasiais axilares; pedicelos 2,0-3,0 mm compr. Brácteas 7,0-8,0 mm compr., 6,07,0 mm larg., elípticas; bractéolas 4,0-5,0 mm compr., 1,0-1,5mm larg., elípticas. Pétalas 7,0-8,0mm compr., 6,0-7,0 mm larg., amarelas, obovadas, ápice obtuso. Hipanto $3,5 \mathrm{~mm}$ compr., campanulado, levemente 10 -costado. Tubo do cálice ca. $0,5 \mathrm{~mm}$ compr.; lacínias ca. 3,0 mm compr., triangulares, persistentes. Estames 10, dimorfos, em duas séries; tecas das anteras ca. 2,0mm compr., levemente encurvadas, rostro ca. $0,2 \mathrm{~mm}$ compr., poros ventralmente inclinados; conectivo dos estames maiores ca. 2,5mm compr., antisépalos, apêndice ca. 1,0 mm compr., projetado ventralmente, bífido, truncado no ápice; filete ca. $4,0 \mathrm{~mm}$ compr., geniculado com o conectivo; conectivo dos estames menores ca. 1,0 mm compr., antipétalos, apêndice curtamente prolongado e bilobado; filetes ca. 3,0mm compr. Ovário ca. 3,0mm compr., globular, 5-locular; estilete ca.. 3,0mm compr.; estigma não expandido. Cápsula ca. 3,5m compr., globular, recoberta pelo hipanto de mesmo comprimento do fruto. Sementes ca. $0,5 \mathrm{~mm}$ compr., subcocleadas, tuberculadas, numerosas por lóculo.

Typus: Brasil, Minas Gerais, Grão-Mogol, Rio das Mortes, coletado em "campo rupestre, ao longo de rio encachoeirado, G. \& M. Hatschbach \& O.S. Ribas 52005, 15.V.1988 (holotypus MBM; isotypus,US).

Figs. 1-6 - Trembleya hatschbachii Wurdack et E. Martins (Pircuni \& Mello-Silva CFCR 10814). 1 - Ramo tlorífero, 2 - Flor com bractéolas, 3 - Estames dos dois ciclos, 4 - Gineceu, 5 - Pétala, 6 - Cápsula recoberta pelo hipanto.

Figs. 1-6 - Trembleya hatschbachii Wurdack et E. Martins (Pirani \& Mello-Silva CFCR 10814). 1 Flowering branch, 2 - Flower with bracteoles, 3 - Stamens (two whorls), 4 - Gynoecium, 5 - Petal, 6 - Capsule recovered by the hypanthium. 


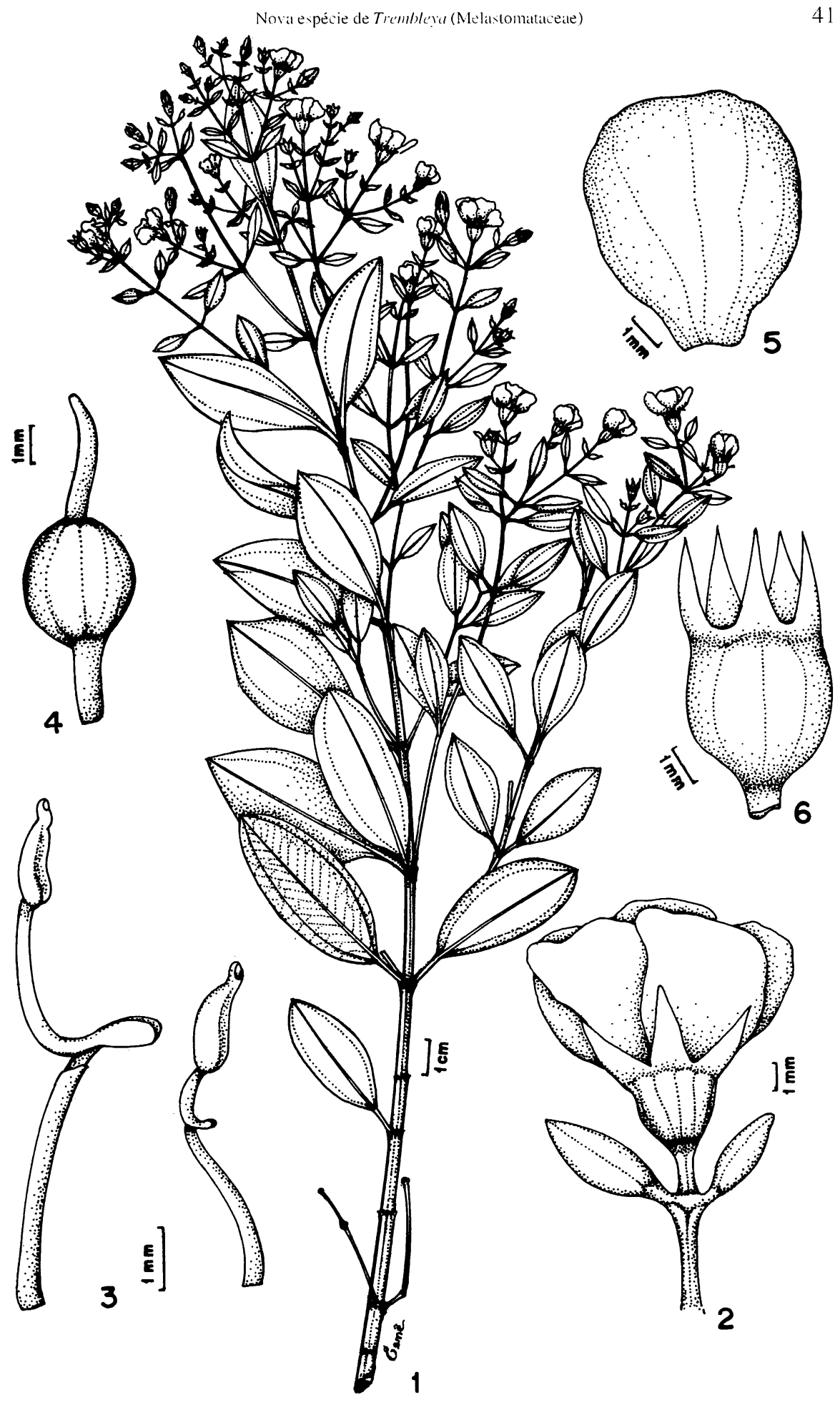


Paratypi: Brasil, Minas Gerais, Grão-Mogol, Rio Itacambiruçu, G. Hatschbach 41337, 21.IV.1978 (MBM, US); Rod. Francisco de Sá, H.F. Leitão Filho et al. 7893, 22.V.1978 (UEC); Grĩo-Mogol, A. Furlan et al.CFCR 771, 12.IV.1981 (UEC, SPF); 2 km SW Grão-Mogol, Vale Ribeirão das Mortes, J.R. Pirani \& R. Mello-Silva CFCR I0814, 23.V.1987 (UEC, SPF); Grão-Mogol,D.C. Zappi et al. CFCR 9906, 24.VII.1986 (UEC, SPF).

\section{COMENTÁRIOS}

Trembleya hatschbachii Wurdack et E. Martins é um táxon bem definido e bastante distinto dos demais já descritos para o gênero, sendo facilmente reconhecido por suas pétalas amarelas e folhas elípticas, laxamente distribuídas ao longo dos ramos.

A espécie, com distribuição restrita até o momento a Grão-Mogol, tem sido encontrada entre rochas próximas a cursos de água.

De acordo com o sistema de Cogniaux (1883), Trembleya hatschbachii é próxima de Trembleya tridentata Naud., por ser uma planta glabra, glutinosa, com panículas dicasiais axilares, diferindo desta por apresentar lâminas foliares maiores e íntegras, lacínias do cálice triangulares, pétalas amarelas obtusas no ápice, apêndices truncado. Trembleya tridentata apresenta lâminas foliares com 2,5-3,5(-4,0)cm compr., 1,2-1,7(-2,0)cm larg. e margem apicalmente denticulada, lacínias do cálice afiladas, pétalas magenta, agudas no ápice, e apêndices ventrais do conectivo dos estames maiores apenas levemente trilobados no ápice. De todas as espécies de Trembleya, até então descritas, somente Trembleya rosmarinoides DC. possui pétalas amarelas. Entretanto, nesta espécie, o ápice das pétalas é agudo; as lâminas foliares uninérveas e bastante estreitas (12,0mm compr., 1,0 mm larg.), concentram-se no terço superior dos ramos. Em T. hatschbachii, as lâminas foliares distribuem-se ao longo de todo o ramo.

\section{AGRADECIMENTOS}

A Dra Angela Borges Martins pela leitura crítica do texto; a Julie H.A. Dutilh e Valéria Stranghetti pela revisão do Abstract; a Esmeralda Zanchetta Borghi pelo auxílio no preparo das ilustrações.

\section{REFERÊNCIAS}

COGNIAUX, A. 1883. Melastomataceae. Tribus I. Microlicieae et tribus II. Tibouchineae. In Martius, C.F.P. de \& Eichler, A.G. (eds.), Flora Brasiliensis 14(3), Lipsiae apud Frid. Fleischer in Comm.. Munique. 